\section{THE MURCHISON MEMORIALS.}

To the Editor of THE LANCET.

SIR,-In your notice of the meeting held at Willis's Rooms on the 5th inst., to organise a memorial to the late Dr. Murchison, there is an inadvertent statement which I should feel grateful if you will allow me to correct. The words of the notice run, "Dr. Greenfield (presumably on behalf of a fund that is being organised at St. Thomas's Hospital for a similar purpose,)" \&c. I am anxious that the very natural error involved in this presumption should be corrected. I stated that I had no connexion with that fund, and had no authority to speak with reference to it. What I said was the outcome of my strong personal feeling, that it would be an advantage that the profession in London should share with Edinburgh in the honour done to one who was essentially a London physician, and that whatever was done should be done in such a way as to perpetuate his memory both in London and Edinburgh.

But whilst the universities' scheme is designed to establish a scholarship in clinical medicine as a public memorial of one whose public work, if I may so term it, was of equal value with, and wider range than, his hospital work, the St. Thomas's Hospital memorial has for its object the perpetuation of his name in connexion with the hospital in which he laboured and taught, and in which his memory as a clinical teacher and a true and wise friend to the students will long be revered. Not unfittingly, the initiation of the latter scheme has been left to the past and present students, who desired thus to give evidence of their regard for their lamented teacher. It has been decided that a bust, as a more personal reminiscence, is the most suitable form for the memorial to take, if sufficient funds can be obtained. Already, by the co-operation of the staff with the old and present students and other friends, a considerable sum has been subscribed or promised for this purpose.

That nothing but harmony reigns between these two memorials is shown by the fact that several of the staff of St. Thomas's, including the president of the committee of the hospital memorial, are also members of the committee of the universities' scheme; and it is a striking testimony to the many-sidedness of Dr. Murchison's character and worth, and the high estimation in which he was held by all who knew him, that two such memorials should have been initiated and have every prospect of success. I am, Sir, yours faithfully,

Palace-road, S.E., June 11th. yours faithfully, G. S. GREENFIELD.

\section{TREATMENT OF GENU VALGUM.}

\section{To the Editor of THE LANCET.}

SIR, - Surely Mr. Brodhurst must have forgotten the exact circumstances that occurred at the Clinical Society. Possibly he has confused the case he brought before the Society with some other treated by osteotomy. I was present at the meeting, and must corroborate the report published in THE LANCET for June 7th. The girl certainly walked into the room with the help of two crutches, with the instrument on, and it was at my request that the instrument on her leg was removed when she was treated. I then found that the limb could not be bent beyond a right angle. When the girl stood up without the apparatus both her hands were supported, and she used her crutches when leaving the room.

I am, Sir, your obedient servant,

Gower-street, June 11th, 1879.

A. Pearce Gould.

\section{THE LARYNGOSCOPE.}

\section{To the Editor of THE LANCET.}

SIR,-Those who use the laryngoscope frequently will find. that a suggestion that has been lately made by a writer in the Union Médicale, as to the employment of glycerine, very practical and convenient in making examinations. He recommends a cloth to be moistened with glycerine, and to be lightly passed over the mirror before use. The water contained in the expired air is completely dissolved in the glycerine, and many examinations can thus be made with- out any heating or warming. I have tried some experiments along with my colleague, Dr. Torrance, and we found that the mirror when so treated could be used for ten or fifteen minutes without being dimmed by the breath or obscurin: the picture.

I am, Sir, your obedient servant,

RichaRd ELLIS,

Hon. Surgeon, Newcastle Throat and Ear Hospital.

June 6th, 1879.

\section{THE ROYAL COLLEGE OF SURGEONS.}

AN ordinary meeting of the Council was held on Thursday, June 12th, the President in the chair. The report of the Committee appointed to consider the mode of conducting the Primary Examinations was presented. After a lengthy and earnest discussion it was carried by fourteen votes (including the President's) to seven that Anatomy and Physiology, as subjects for examination, should be separated, and that the next nomination of examiners should be made on this principle.

Messrs. Parker, Flower, Lowne, and Hutchinson were nominated for re-election as Professors and Lecturers at the College.

A petition from one hundred Fellows in favour of granting the power of voting by proxy at the elections for the Council was presented, but it was stated that it was contrary to the charter to accede to it.

The report of the Erasmus Wilson Trust Committee was presented, and ordered to be entered on the minutes. The thanks of the Council having been voted to Sir James Paget for the presentation to the College of twenty-six autograph letters of Hunter to Jeuner, the Council adjourned til Thursday, the 19th inst., when the President's report will be presented, and the consideration of the remainder of the report of the Committee on the Primary Examinations will be resumed.

\section{PARLTAMENTARY PROCEEDINGS.}

\section{HOUSE OF COMMONS.}

Wednesday, June 11th.

CON TAGIOUS DISEASES.

On the motion of Colonel STANLEY, a select committee was appointed to inquire into the Contagious Diseases Acts (1866-9), their administration, operation, and effect; and the following members were appointed to serve on the committee :- Mr. Cavendish Bentinck, Mr. Stansfeld, Colonel Alexander, Sir Harcourt Johnstone, Viscount Crichton, Mr. Shaw Lefevre, General Shute, Mr. Burt, Mr. Bulwer, Mr. O'Shaughnessy, together with five mem. bers to be nominated by the committee of selection,

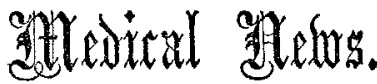

Royal College of Surgeons of England. The following Members, having passed the required examination for the Fellowship on May 29th, 30th, and 31st, were, at a meeting of the Council held on Thursday last, duly admitted Fellows of the College :-

Andrews, William Stratford, Castle-street, Dover ; diploma of Membership dated May, 1878.

Cathcart, Charles Walker, M..A., M.B., C.M. Edin., Carlton-terrace, Edinburgh. (Not a Member.)

Cheyne, William Watson, M.B. Edin., old Cavendish-street. (Not a Member.)

Clarke, William
May, 1877.
Footner, John

Footner, John Bulkley, Romsey, Hants ; Jannary, 1875.

Juler, Henry Edward, L.S.A., St. Mary's Hospital; May, 1867.

Lang, William, Exeter ; January, 1874.

Morgan, John, L.R.C.P. Lond., Hereford-road, Bayswater; Nov. 1860 Ca, George Edwan,

Three candidates failed to reach the required standard, and were referred for twelve months' further professional study. 